\title{
A TRIBUTAÇÃO INTERNACIONAL DOS PREÇOS DE TRANSFERÊNCIA \\ A Contribuição da OCDE
}

Adriano da Nobrega Silva

\section{RESUMO}

O presente trabalho tem por objeto apresentar brevemente a contribuição da OCDE no que se refere à questão da dupla tributação internacional da renda e da imposição fiscal sobre os preços de transferência internacionais.

Palavras-Chaves: OCDE; dupla tributação internacional; preços de transferência internacionais. 


\section{INTRODUÇÃO}

O fenômeno da globalização traz importantes conseqüências em todos os campos sociais, especialmente no econômico. Um de seus reflexos mais imediatos é o aumento das transações internacionais, mormente as realizadas intercompanhias ou entre partes relacionadas. Isso traz implicações no poder tributante dos Estados, especialmente em relação ao que vem sendo denominado na doutrina especializada de preços de transferência.

O objeto do presente estudo é a contextualização da temática dos preços de transferência e suas relações com o problema da dupla tributação internacional. Para tanto, serão abordados:

a) os fatores que levam uma empresa a investir no plano internacional;

c) a possibilidade de tributação de lucros tramsnacionais, tanto no Estado em que se localiza a fonte dos rendimentos como naquele em que está situada a residência da empresa investidora, com a conseqüente dupla tributação internacional dos mesmos lucros e a oneração em demasia das empresas multinacionais;

d) a inadequação da via unilateral para a resolução de tal problema;

d) os mecanismos bilaterais que podem ser utilizados para evitar essa dupla tributação;

e) a utilização do princípio da livre concorrência como parâmetro para a definição da parcela de lucros gerada em cada Estado; e

f) uma breve exposição sobre a contribuição da OCDE no que se refere à forma proposta em seu Modelo de Convenção para a tributação dos lucros e para a determinação dos preços de transferência.

\section{GLOBALIZAÇÃO ECONÔMICA E DUPLA TRIBUTAÇÃO INTERNACIONAL}

No início do século XX, os principais países industrializados haviam atingido elevado grau de integração econômica. Entretanto, o mesmo foi de certo modo paralisado após a I Guerra Mundial, tendo diversos países instituído elevadas barreiras tarifárias ao 
comércio internacional. A II Guerra Mundial também dificultou a realização de investimentos internacionais, com a devastação em larga escala dos meios de produção ${ }^{1}$.

O movimento de integração econômica começou a ser recuperado a partir da década de 50, tendo, atualmente, atingido níveis expressivos, ao se constatar que 65 mil empresas são transnacionais, operando por meio de 850 mil filiais, detendo um patrimônio de US\$ 25 trilhões, sendo responsáveis por 54 milhões de empregos, auferindo um faturamento de US\$ 19 trilhões e realizando 66\% das exportações mundiais, o que evidencia que a globalização decorre não só de questões macroeconômicas, mas também de aspectos microeconômicos ${ }^{2}$.

A realização de investimentos privados no exterior se dá em virtude de dois principais objetivos: a busca de maior segurança do investimento - a qual leva em conta não apenas questões econômicas, mas também o que recentemente vêm sido denominado como risco país - bem como a busca de maior rentabilidade para o investimento - a qual vai depender do desempenho da economia do país no qual foi realizado o investimento e também das políticas reguladoras dos governos envolvidos ${ }^{3}$. Além desses aspectos, podem ser apontados, ainda, a crescente liberalização ocorrida na maior parte dos países e a criação de blocos regionais ${ }^{4}$.

Pode-se afirmar que, ao investir no plano internacional, a empresa leva em conta o fato de possuir vantagens monopolísticas ou de ser titular de direitos exclusivos que a tornem competitiva em outros mercados, bem como considera a possibilidade de internalizar os resultados de sua atividade internacional, sendo, portanto, esse investimento uma das formas de melhor organizar suas atividades como forma de minimizar seus custos 5 .

Nesse cenário, a tributação adquire uma dupla importância: os países precisam conciliar o interesse em taxar os lucros provenientes de seus territórios ao mesmo tempo em

1 UNITED NATIONS. Draft manual for the negociation of bilateral tax treaties between developed and developing countries. New York: United Nations: 2001. Disponível em <www.unpan.org> Acesso em 28 out 2003, p. 4.

2 LACERDA, Antônio Correa de. Os Fluxos de investimentos e o papel das empresas transacionais. In Política Externa, vol. 12, no 2. set/out/nov 2003, p. 6.

3 HINOJOSA MARTÍNEZ, Luis Miguel. La Regulación de los movimientos internacionales de capital desde una perspectiva europea. Madrid: McGraw Hill, 1997, p. 12.

4 LACERDA, Antônio Correa de. Os Fluxos de investimentos e o papel das empresas transacionais. In Política Externa, vol. 12, n- 2. set/out/nov 2003, p.7. 
que devem buscar modos de impedir a incidência de diversos impostos, provenientes de mais de uma jurisdição fiscal, sobre a mesma renda ${ }^{6}$.

É possível a tributação de uma mesma renda em mais de um ordenamento jurídico sempre que se verifica a conexão de ambos. Para a identificação dos possíveis elementos de conexão entre ordenamentos jurídicos distintos, deve ser tomado em consideração um dos seguintes aspectos: o(s) sujeitos envolvidos, o objeto da relação jurídica e o ato jurídico praticado ${ }^{7}$. No plano tributário, relevam, quanto ao sujeito, os critérios da nacionalidade ou da residência e, quanto ao objeto da relação jurídica, o critério da fonte dos rendimentos, detalhados a seguir.

\subsection{O PRINCÍPIO DA TRIBUTAÇÃO SEGUNDO A RESIDÊNCIA}

Este é o princípio segundo o qual os indivíduos e as pessoas jurídicas são tributados no país de sua residência, ou seja, a qualidade de residente em determinado país é determinante para a identificação do regime tributário aplicável. É necessário, portanto, que se defina quem tem, ou não, esta qualidade.

Nesse sentido, o modelo de Convenção da OCDE define residente como qualquer pessoa a qual, em observância às leis de seu Estado, encontra-se obrigada ao pagamento de tributo em razão de domicílio, residência, sede de direção ou outro critério assemelhado ${ }^{8}$.

A seguir, estabelece que, quando houver definição de residência para um indivíduo em mais de um dos Estados contratantes, essa será definida do seguinte modo ${ }^{9}$ :

a) esta pessoa será considerada do Estado Contratante em que disponha de uma habitação permanente. Se dispuser de uma habitação permanente em ambos os Estados Contratantes, será considerada como residente do estado contratante com o qual suas ligações pessoais e econômicas sejam mais estreitas (centro de interesses vitais);

5 SAlA GAlVAN, Gemma. Los Precios de transferencia internacionales: su tratamento tributario. Valencia: Tirant lo Blanch, 2003, p. 39.

6 ORGANISATION FOR ECONOMIC CO-OPERATION AND DEVELOPMENT (OECD). Transfer Pricing: Guidelines for Multinational Enterprises and Tax Administrations. Paris: OECD, 2001. p. P-1.

7 DOLLINGER, Jacob. Direito Internacional Privado: parte geral. $5^{\mathrm{a}}$ ed., atualizada. Rio de Janeiro: Renovar, 2000, p. 262.

8 ORGANISATION FOR ECONOMIC CO- OPERATION AND DEVELOPMENT. Articles of the model convention with respect to taxes on income and on capital: as they read on 28 January 2003. Disponível em <www.oecd.org > Acesso em 24 set 2003. Art. 4, Item 1.

9 Idem, Art. 4, Item 2. 
b) se o Estado Contratante em que tem o centro de seus interesses vitais não puder ser determinado, ou se não dispuser de uma habitação permanente em nenhum dos Estados Contratantes, será considerada como residente do Estado Contratante em que permanecer habitualmente;

c) se permanecer habitualmente em ambos os Estados Contratantes ou se não permanecer habitualmente em nenhum deles, será considerada como residente do Estado Contratante de que for nacional;

d) se for nacional de ambos os Estados Contratantes ou se não for nacional de nenhum deles, as autoridades competentes dos estados contratantes resolverão a questão de comum acordo.

No caso de pessoas jurídicas ou outras entidades residentes de ambos os Estados Contratantes, estas serão consideradas residentes do Estado contratante em que estiver situada a sua sede de direção efetiva ${ }^{10}$.

\subsection{O PRINCÍPIO DA TRIBUTAÇÃO NA FONTE}

Em relação aos impostos sobre a renda e sobre o capital, há, na definição de seus respectivos fatos geradores, uma relação jurídica que consiste no auferimento, conforme o caso, de renda ou de capital por residentes ou não em determinado Estado. Caso tal auferimento se dê por um residente, o mesmo se encontra sujeito aos impostos em função de sua residência e, portanto, há conexão com apenas um ordenamento jurídico, não se tratando, no caso, de questão a ser solucionada pelo Direito Internacional.

Contudo, a situação se modifica quando se trata de tal auferimento por nãoresidentes. Se está, nesse caso, diante de uma relação jurídica em que a fonte dos rendimentos ou do capital auferido se localiza em um Estado que não o da residência do beneficiário. Nesse caso, os países importadores de investimentos tributam tais rendas ou benefícios do capital justamente por haver a conexão da fonte pagadora com seus respectivos ordenamentos jurídicos ${ }^{11}$.

10 Idem, Art. 4, Item 3.

11 É interessante a crítica que Klaus Vogel apresenta à tributação no Estado da fonte. Segundo ele, há uma incongruência em tal exigência de tributo: se o residente no Estado paga um imposto pelo fato de viver no país, ao passo que o não-residente paga outro, pelo fato de obter rendimento produzido em fonte local, não há como explicar porque o residente não deve, também, pagar este outro imposto, tendo em vista que ele vive no Estado e seus rendimentos são nele produzidos. Assim, constata Vogel que o legislador, ao definir que parte 


\subsection{RESOLUÇÃO DO PROBLEMA}

Caso um Estado promova a tributação de seus residentes (a chamada sujeição passiva plena) e outro Estado promova a tributação dos não-residentes na medida em que os rendimentos ou frutos do capital provenham de fontes situadas em seus territórios (a chamada sujeição passiva limitada), haverá dupla tributação internacional na medida em que o residente do primeiro Estado aufira rendimentos provenientes do segundo.

Obviamente, os Estados exportadores de investimentos - em sua maioria, países desenvolvidos - têm interesse em que os residentes em seus territórios sejam tributados apenas segundo o princípio da residência, ao passo que os importadores de investimentos - grupo constituído, em grande parte, por países em vias de desenvolvimento - tendem a aplicar a tributação dos não-residentes segundo o princípio da fonte.

Uma das formas de se solucionar a questão da dupla tributação internacional é a adoção de medidas unilaterais (internas), tais como:

- A concessão de isenção, ao se definir a base de cálculo do imposto, de toda ou parte da renda ou patrimônio proveniente de fonte estrangeira, exigindo-se, normalmente, que os citados fatos econômicos tenham sido tributados efetivamente no outro Estado;

- A atribuição ao residente do país de um crédito com base no valor do tributo devido no estrangeiro;

- Permitir a dedução, na base de cálculo do imposto, do valor do tributo pago no exterior; e

- O Estado da fonte prever uma redução da alíquota do imposto se a renda ou os capitais situados no exterior são tributados no país da residência. ${ }^{12}$

Diz-se que os Estados que promovem a tributação das rendas obtidas por seus residentes no exterior adotam o princípio da world-wide income taxation, ou princípio da tributação em bases universais, ao passo que aqueles que promovem a isenção ou,

da capacidade contributiva está sujeita ao imposto, respondeu de modo diverso ao se ter em conta os residentes e os não-residentes. As críticas do autor são procedentes ao se ter em conta a inexistência de meios para evitar a dupla tributação, pois, neste caso, há carga tributária uniforme tanto sobre o residente quanto sobre o não-residente. (VOGEL, Klaus. Tributação da Renda Mundial. In: Cadernos de Direito Tributário e Finanças Públicas. Ano 2, número 7. São Paulo: Revista dos Tribunais, 1994, pp. 113-143).

12 GARCÍA, Nicolás Sánchez. La doble imposición internacional. In: Revista de Treball, Economia i Societat. número 16. Castelon: janeiro/ 2000. Disponível em <www.ces-cv.es/articulos_revista/ Revista_16/art2-rev16.pdf> Acesso em 9 out 2003. 
simplesmente, não prevêem a incidência de tributo interno nesses casos adotam o chamado princípio da territorialidade ${ }^{13}$.

Outra possibilidade é a adoção de medidas bilaterais (por meio de convenções internacionais), a exemplo das seguintes:

a) Concessão de isenção:

- Plena: o Estado, ao exigir o imposto de seus residentes, não inclui na base de cálculo para todos os fins as rendas que já tenham sofrido tributação por força da Convenção firmada.

- Parcial, com a aplicação de alíquota efetiva: em relação aos impostos progressivos, as rendas obtidas no exterior são isentas do tributo, mas as mesmas são levadas em conta no momento da aplicação da alíquota sobre a base de cálculo tributável que será declarada pelo sujeito passivo.

b) Métodos de imputação do pagamento do tributo:

- Plena: o Estado da residência permitirá a dedução do imposto a pagar dos tributos pagos no estrangeiro, sem nenhum tipo de limitação, incluindo-se na base de cálculo do imposto nacional todas as rendas do sujeito passivo residente.

- Limitada: o crédito devido sobre os impostos pagos no estrangeiro não poderá exceder o montante do tributo devido no Estado da residência após o computo das correspondentes rendas obtidas no exterior. ${ }^{14}$

\section{O PRINCÍPIO DA LIVRE CONCORRÊNCIA}

Antes, porém, de determinar a distribuição da carga tributária, é necessária a definição da parcela de lucros que está sujeita à jurisdição fiscal de cada Estado em que houve conexão com os rendimentos produzidos.

Tendo em conta, como já se afirmou, que a maior parte das transações internacionais é realizada entre entidades empresariais vinculadas, para se definir o montante dos lucros de cada uma pode-se adotar dois critérios: considerar as diversas entidades como um negócio unitário (unitary business), ou como entidades independentes.

13 Atualmente são poucos os Estados que adotam o princípio da territorialidade. Podem ser mencionados: Bolívia, Costa Rica, El Salvador, Guatemala, Hong Kong SAR, Quênia, Malaísia, Nicarágua, Panamá, Paraguai, Cingapura e Uruguai. (UNITED NATIONS. Manual for the negociation of bilateral tax treaties between developed and developing countries. New York: United Nations: 2003. Disponível em <www.unpan.org> Acesso em 28 out 2003.) 
A primeira hipótese tem como premissas o fato de as atividades econômicas desenvolvidas por cada unidade contribuírem para os lucros totais de todo o grupo, bem assim em virtude dos efeitos sinérgicos da atividade econômica para o grupo como um todo, visto que o resultado global é maior que a soma das atividades individuais consideradas isoladamente.

Nesse caso, a tributação é realizada sobre a totalidade dos lucros apurados, desconsideradas as transações intra-grupo, dando-se a repartição dos resultados, para efeito de tributação pelas diferentes jurisdições fiscais, mediante á-se rateio com base nas atividades econômicas desenvolvidas em cada Estado em relação às atividades econômicas totais $^{15}$.

Ainda que tal forma tenha sido utilizada em legislações estatais internas para a resolução da questão da dupla tributação internacional, bem como tenha sido levada em conta no âmbito dos primeiros trabalhos desenvolvidos pela Sociedade das Nações para a resolução bilateral dos conflitos, a mesma foi abandonada a partir do Informe Carroll de $1933^{16}$, em virtude das seguintes objeções ${ }^{17}$ :

- a jurisdição fiscal deve restringir sua soberania às fontes de renda existentes em seu território;

- havia diferenças entre as normas tributárias e empresariais existentes nos diferentes Estados quanto a métodos e conceitos contábeis e a problemas de avaliação e troca de ativos tornariam inviável a aplicável do método do conceito unitário; e

- havia dificuldades inerentes à possibilidade de se chegar a um acordo internacional sobre os lucros do negócio unitário e às bases de rateio do mesmo, associadas à reação dos Estados ao se deparar com a diminuição dos lucros que poderiam tributar; e

- a maior parte das jurisdições fiscais e a Câmara Internacional de Comércio demonstraram preferência por considerar as entidades como independentes, ou seja, mostraram-se partidários à adoção do princípio da livre concorrência, ou arm's length.

14 GARCíA, Nicolás Sánchez. La doble imposición internacional. In: Revista de Treball, Economia i Societat. número 16. Castelon: janeiro/ 2000. Disponível em <www.ces-cv.es/articulos_revista/ Revista_16/art2-rev16.pdf> Acesso em 9 out 2003.

15 SALA GALVAN, Gemma. Los Precios de transferencia internacionales: su tratamento tributario. Valencia: Tirant lo Blanch, 2003, p. 53.

16 Trata-se do relatório Taxation of Foreign and National Enterprises, elaborado por Mitchell B. Carroll, em especial seu volume IV: Methods of Allocating Taxable Income. 
Como pressuposto da aplicação do princípio da livre concorrência, está a consideração das duas partes envolvidas no negócio como empresas independentes. Assim sendo, as operações devem ser realizadas o mais próximo possível das condições de livre mercado. Eventuais distorções nos lucros decorrentes de vínculos entre as empresas devem ser eliminadas.

Segundo as clássicas lições de Adam Smith, há uma distinção entre o preço natural do produto, qual seja, aquele suficiente para pagar os fatores produtivos - a renda da terra, os salários do trabalho e os lucros do patrimônio ou capital empregado em obter, preparar e levar a mercadoria ao mercado - e o chamado preço de mercado, ou seja, o preço efetivo ao qual uma mercadoria é vendida, o qual pode estar acima ou abaixo do preço natural, podendo também coincidir exatamente com ele, sendo regulado pela proporção entre a quantidade que é efetivamente colocada no mercado e a demanda daqueles que estão dispostos a pagar o preço natural da mercadoria ${ }^{18}$.

Até o início do século XIX, pode-se afirmar que todas as operações eram realizadas no mercado, entre o empresário e pessoas externas à sua organização fornecedores de matéria-prima, mão-de-obra paga por tarefa e clientes. Nesse panorama, o sucesso ou não do empreendimento era facilmente verificável, sendo obtido a partir do cotejo entre os valores obtidos por meio das vendas e aqueles utilizados para a remuneração dos fatores de produção ${ }^{19}$.

A Revolução Industrial, os avanços nos meios de transporte e nas comunicações verificados desde o século XIX permitiram o desenvolvimento de grandes organizações hierárquicas, com melhores oportunidades de aproveitar as economias de escala verificadas nos processos produtivos ${ }^{20}$. Os agentes econômicos, em sua busca por uma maior otimização dos recursos, passaram a organizar suas atividades por meio de filiais e sucursais, bem assim por meio da aquisição de participação societária ou mesmo de controle acionário em outras sociedades, as chamadas coligadas e controladas.

17 SAla GalVAN, Gemma. Los Precios de transferencia internacionales: su tratamento tributario. Valencia: Tirant lo Blanch, 2003, p. 77.

18 SMITH, Adam. A Riqueza das nações: Investigação sobre sua natureza e suas causas. Introdução de Edwin Cannan, apresentação de Winston Fritsch e tradução de Luiz João Baraúna. In Os Economistas. São Paulo: Nova Cultural, 1996. v. I, pp. 109 e 110.

19 JOHNSON, H. Thomas. KAPLAN, Robert S. Contabilidade gerencial: a restauração da relevância da contabilidade nas empresas. Tradução de Ivo Koryotowski. Rio de Janeiro: Campus, 1993, p. 8.

20 JOHNSON, H. Thomas. KAPLAN, Robert S. Op. cit., p. 9. 
Pouco a pouco, o comércio passou a ser realizado em escalas mundiais, sendo essa internacionalização hoje um fenômeno inquestionável. Os anteriores agentes independentes tornaram-se departamentos de uma mesma entidade empresarial. As compras e vendas de insumos se transformaram em meras transferências entre repartições da mesma organização. Quando do envio de um insumo, por exemplo, de uma filial para a sua matriz, ocorre um fato econômico que deve ser refletido pelos sistemas de informações contábeis. O valor dessa operação não é mais determinado pelo preço de mercado, dado que inexistiu compra ou venda, mas sim pela própria companhia, razão pela qual se denomina tal preço como preço de transferência ${ }^{21}$.

Os preços de transferência, sobretudo em entidades empresarias altamente descentralizadas, são necessários para o adequado controle de suas operações internas, assegurando a distribuição ótima dos recursos e possibilitando o acompanhamento da eficiência de suas unidades, por permitir avaliar a gestão e a avaliação de seus resultados econômicos ${ }^{22}$.

Entretanto, ainda que se reconheça que as empresas associadas, ao negociarem entre si, procurem reproduzir a dinâmica das forças de mercado, suas relações comerciais e financeiras não são afetadas pelo mercado do mesmo modo que entidades independentes. Se isso é verdadeiro ao se tratar de empresas atuando dentro de um único Estado, tal fato é ainda mais evidente ao se tratar de empresas multinacionais (Multinational enterprises MNEs) $)^{23}$.

Diversos fatores, além das questões estritamente fiscais, podem provocar distorções nos preços de transferência, de modo a que não reflitam exatamente os preços de mercado:

Por exemplo, tais empresas podem estar sujeitas a pressões governamentais diversas, tanto de seu país de origem quanto a do país importador, relacionadas a valoração

\footnotetext{
21 Por essa razão, apesar da conotação de modo de majoração de lucros e diminuição da carga fiscal sofrida pela empresa ao se tratar de preços de transferência no âmbito do direito tributário, se deve afirmar ser este um conceito neutro, indicando os preços pelos quais "se entregam bens tangíveis (acabados ou em fase intermediária de produção), se prestam serviços ou se distribuem recursos entre empresas vinculadas”. SALA GALVAN, Gemma. Los Precios de transferencia internacionales: su tratamento tributario. Valencia: Tirant lo Blanch, 2003, p. 42, livre tradução do autor.

22 SALA GALVAN, Gemma. Los Precios de transferencia internacionales: su tratamento tributario. Valencia: Tirant lo Blanch, 2003, p. 42, livre tradução do autor.

23 Conforme a clássica expressão utilizada no âmbito da Organização para Cooperação e Desenvolvimento Econômico (OCDE).
} 
aduaneira, normas antidumping, normas relacionadas ao controle da taxa de câmbio e mesmo de controle de preços. Em adição, as distorções nos preços de transferência podem ser causadas por questões relacionadas ao fluxo de caixa da empresa multinacional. Um grupo multinacional que negocia títulos no mercado de valores mobiliários pode sofrer pressões dos acionistas para mostrar alta lucratividade no nível mais alto da companhia, principalmente se as demonstrações contábeis dirigidas aos acionistas não são realizadas de modo consolidado. Todos esses fatores podem afetar os preços de transferência e o montante dos lucros das empresas associadas de um grupo multinacional ${ }^{24}$.

Isso explica porque o princípio surge, inicialmente, em diversos países da Europa Continental - a exemplo da Áustria, Alemanha, Luxemburgo, Holanda e Suíça para o ajuste da renda dos acionistas que recebiam distribuições extraordinárias de recursos de companhias que não haviam sido oficialmente declarados como dividendos. Os acionistas majoritários podiam promover tais distribuições em virtude de sua especial posição na companhia. Nesses casos, era realizado um ajuste considerando que havia ocorrido, no caso, distribuição disfarçada de dividendos, os quais não eram dedutíveis dos resultados da Companhia. Nota-se que o foco do ajuste era, nessas circunstâncias, essencialmente relacionado com a legislação doméstica.

Regras sobre transferência de preços visando operações internacionais surgem durante a I Guerra Mundial no Reino Unido e nos Estados Unidos com o propósito de evitar a evasão fiscal, o que se dava em virtude de as companhias super ou sobrevalorizarem os preços nas operações com empresas associadas localizadas em outros Estados.

O interesse, nos dois casos, é neutralizar as distorções provocadas pela associação entre as partes, a fim de assegurar um igual tratamento entre os acionistas controladores e os demais acionistas, ou entre os contribuintes que controlam diversas outras empresas em relação aos que não participam desse modo no mercado ${ }^{25}$.

24 ORGANISATION FOR ECONOMIC CO-OPERATION AND DEVELOPMENT (OECD). Transfer Pricing Guidelines for Multinational Enterprises and Tax Administrations. Paris: OECD, 1995, p. I-2. Tradução livre do autor.

25 UNITED NATIONS. Transfer Pricing : History - State of the Art - Perspectives. Ad Hoc Group of Experts on International Cooperation in Tax Matters. Tenth meeting. Geneva, 10 - 14 September 2001. Disponível em <www.un.org> Acesso em 8 setembro 2003. 
As medidas de caráter fiscal tomadas isoladamente por determinados Estados, por um lado, pareciam proteger de modo imediato os interesses daquele país que as adotasse, mas por outro se revelavam inadequadas justamente por onerar em demasia os agentes econômicos envolvidos, conforme se demonstrará a seguir.

\section{3, AJUSTE UNILATERAL DOS PREÇOS DE TRANSFERÊNCIA}

Um dos princípios que deve reger a tributação elaborados por Adam Smith é o conhecido princípio da neutralidade, segundo o qual os impostos devem ser planejados de modo a retirar dos contribuintes o mínimo possível além de seu próprio valor, sendo uma das formas mencionadas por ele pela qual o tributo pode se tornar mais oneroso do que o valor efetivamente arrecadado é quando ele dificulta a iniciativa dos contribuintes e dificulta a aplicação de recursos em setores da economia ${ }^{26}$.

Tal é o que ocorre com os ajustes de preços de transferência por medidas unilaterais. A fim de demonstrar tal fato, considere-se o seguinte exemplo hipotético:

A Argentina tributa a renda das empresas a uma alíquota de $20 \%$, ao passo que o Brasil o faz a uma alíquota de $10 \%$. O preço de venda, em condições de livre concorrência, de couro na Argentina é de 200 unidades monetárias por tonelada, ao passo que no Brasil, o preço de revenda é de 300 unidades monetárias. O custo de fabricação é de 100 unidades monetárias.

Assim, em condições de livre concorrência, ter-se-ia o seguinte panorama:

\begin{tabular}{|l|r|r|r|}
\cline { 2 - 3 } \multicolumn{1}{c|}{} & Argentina & Brasil & Carga Fiscal \\
\hline Preço de Venda & 200,00 & 300,00 & \\
\hline Custo & $(100,00)$ & $(200,00)$ & \\
\hline Lucro & 100,00 & 100,00 & \\
\hline Alíquota do IR & $20 \%$ & $10 \%$ & \\
\hline IR Devido & 20,00 & 10,00 & 30,00 \\
\hline
\end{tabular}

Ocorre que a empresa argentina, ao pretender exportar seus produtos para o Brasil, encontra-se em franca condição de desvantagem, ao se ter em conta a carga fiscal por ela suportada, considerando-se que as empresas brasileiras podem fabricar o produto no

26 SMITH, Adam. A Riqueza das nações: Investigação sobre sua natureza e suas causas. Introdução de Edwin Cannan, apresentação de Winston Fritsch e tradução de Luiz João Baraúna. In Os Economistas. São Paulo: Nova Cultural, 1996. v. II, p. 283. 
mercado interno ao mesmo preço, pois a empresa brasileira teria a seguinte estrutura de custos:

\begin{tabular}{|l|r|r|}
\cline { 2 - 3 } \multicolumn{1}{c|}{} & \multicolumn{1}{c|}{ Brasil } & Carga Fiscal \\
\hline Preço de Venda & 300,00 & \\
\hline Custo & $(100,00)$ & \\
\hline Lucro & 200,00 & \\
\hline Alíquota do IR & $10 \%$ & \\
\hline IR Devido & 20,00 & 20,00 \\
\hline
\end{tabular}

Para minimizar sua carga fiscal e tornar-se competitiva nas exportações, a empresa Argentina ao negociar com outra empresa associada no Brasil passa a realizar as exportações ao preço de 100,00 unidades monetárias ${ }^{27}$. Tem-se, então, a seguinte configuração de custos:

\begin{tabular}{|l|r|r|r|}
\cline { 2 - 3 } \multicolumn{1}{c|}{} & Argentina & \multicolumn{1}{c|}{ Brasil } & Carga Fiscal \\
\hline Preço de Venda & 100,00 & 300,00 & \\
\hline Custo & $(100,00)$ & $(100,00)$ & \\
\hline Lucro & 0,00 & 200,00 & \\
\hline Alíquota do IR & $20 \%$ & $10 \%$ & \\
\hline IR Devido & 0,00 & 20,00 & 20,00 \\
\hline
\end{tabular}

A carga fiscal se igualou, mas o Governo Argentino perdeu as 20 unidades monetárias de arrecadação que até então detinha. Como forma de evitar essa evasão, esse país implementa, por meio de legislação interna, normas relativas a ajustes de preços para efeitos fiscais, de forma a trazê-los novamente às condições de livre mercado.

Assim, os resultados contábeis da empresa passariam a ser os seguintes:

\begin{tabular}{|l|r|r|r|}
\cline { 2 - 3 } \multicolumn{1}{c|}{} & Argentina & \multicolumn{1}{c|}{ Brasil } & Carga Fiscal \\
\hline Preço de Venda & 100,00 & 300,00 & \\
\hline Custo & $(100,00)$ & $(100,00)$ & \\
\hline Lucro contábil & 0,00 & 200,00 & \\
\hline Ajuste fiscal & 100,00 & $---x x x--$ & \\
\hline Alíquota do IR & $20 \%$ & $10 \%$ & \\
\hline IR Devido & 20,00 & 20,00 & 40,00 \\
\hline
\end{tabular}

Com isso, o Governo argentino recupera suas 20,00 unidades monetárias de arrecadação, mas a companhia passa a estar em desvantagem ainda maior em relação às brasileiras, pois o Governo brasileiro não é obrigado a promover qualquer ajuste nos lucros

27 Parte-se da premissa, obviamente, que o preço praticado não se sujeitaria a qualquer legislação brasileira antidumping. 
da empresa, com o intuito de reduzi-lo, tendo em vista tratar-se de medida unilateral tomada pelo outro Estado.

\section{AJUSTE BILATERAL: A CONTRIBUIÇÃO DA OCDE}

Como forma de solucionar adequadamente a questão do ajuste dos preços de transferência tem-se a possibilidade de celebração de convenções internacionais, as quais regularão a competência de cada ente tributante ${ }^{28}$. Essa questão tem sido objeto de preocupação por parte dos Estados desde os pioneiros trabalhos desenvolvidos na década de 1920 pela Sociedade das Nações, sendo que uma das mais importantes contribuições na área é a que vem sendo desenvolvida pela Organização para a Cooperação e Desenvolvimento Econômico (OCDE).

\subsection{INTRODUÇÃO}

A Organização para a Cooperação Econômica Européia (OECE) ${ }^{29}$ criou em 1956 um Comitê Fiscal a fim de oferecer propostas para os problemas relativos à dupla tributação em seus países-membros mediante formas que pudessem ser, posteriormente, ampliadas para outros Estados. Tal se deu porque a maior integração econômica verificada após a II Guerra Mundial tornou inapropriadas as Convenções firmadas até então ${ }^{30}$, sobretudo as baseadas no modelo de Convenção elaborado no México pela Sociedade das Nações ${ }^{31}$.

Como resultado desses estudos, foi elaborado um modelo de Convenção, já no âmbito da OCDE, o qual foi publicado originalmente em 1963, sendo revisado a partir de 1967. Dez anos depois, foi novamente publicado, sob a forma revisada, tendo prosseguido a

\footnotetext{
28 Segundo a lição de Alberto Xavier, as normas de reconhecimento de competência dividem-se em dois grandes grupos: as de reconhecimento exclusivo e as de reconhecimento cumulativo. As primeiras atribuem o poder de tributar a apenas uma entidade tributante, ao passo que as últimas reconhecem tal poder a diversas entidades, conforme a conexão dos fatos econômicos ensejadores de obrigação tributária com os seus respectivos ordenamentos (XAVIER, Alberto. Direito Tributário Internacional do Brasil: tributação das operações internacionais. $5^{a}$ ed., atualizada. Rio de Janeiro: Forense, 2000, p. 542).

29 A qual mais tarde se tornou a OCDE.

30 UNITED NATIONS. Manual for the negociation of bilateral tax treaties between developed and developing countries. New York: United Nations: 2003. Disponível em <www.unpan.org> Acesso em 28 out 2003.

31 O Modelo de Convenção Mexicana encontra-se disponível em <http://www.law.wayne.edu/Faculty/ Fac_web/mcintyre/text/Treaty_Class/mexico.pdf> Acesso em 08 jan 2004.
} 
atualização, sendo publicado um novo modelo em 1992, a qual fora objeto de revisões em 1994, 1995, 1997, 2000 e 2003.

O modelo de Convenção da OCDE baseia-se em duas premissas: o país da residência elimina a dupla tributação a partir do crédito do imposto pago no país da fonte e este, por seu turno, irá restringir sua jurisdição fiscal à tributação das rendas provenientes de fontes situadas em seu território e utilizar alíquotas mais baixas quando utilizar essa competência tributante ${ }^{32}$.

As principais disposições que envolvem a discussão sobre preços de transferência são as previstas nos arts. 5, 7, 9 e 23. Iniciar-se-á o estudo a partir do Artigo 7, o qual regula o tratamento tributário dos lucros empresariais.

\subsection{O CONCEITO DE ESTABELECIMENTO PERMANENTE}

A primeira parte do Artigo 7 estabelece que os lucros de uma empresa de um Estado Contratante só são tributáveis nesse Estado, a não ser que a empresa exerça sua atividade no outro Estado Contratante por meio de um estabelecimento permanente aí situado. Assim, um conceito-chave, portanto, para o entendimento do adequado tratamento tributário previsto para os lucros internacionais - e, por decorrência, do previsto para os preços de transferência - é o de estabelecimento permanente, cuja definição se encontra no art. 5o do Modelo de Convenção. A regra geral é a de que este se constitui em uma instalação fixa de negócios em que a empresa exerça toda ou parte de sua atividade.

Procurando aclarar o conceito, o mesmo artigo estabelece de modo exemplificativo que a expressão abrange especialmente: a sede de direção, uma sucursal, um escritório, uma fábrica, uma oficina, uma mina, um poço de gás ou de petróleo, uma pedreira ou qualquer outro local de extração de recurso naturais.

Quanto aos canteiros de obras e construções, ou aos projetos de instalação, os mesmos somente serão considerados estabelecimentos permanentes caso os respectivos serviços excedam o período de doze meses.

No mesmo intuito exemplificativo, o Modelo de Convenção estabelece que não se consideram estabelecimentos permanentes: as instalações utilizadas unicamente para fins

32 UNITED NATIONS. Manual for the negociation of bilateral tax treaties between developed and developing countries. New York: United Nations: 2003. Disponível em <www.unpan.org> Acesso em 28 out 2003. 
de armazenagem, exposição e entrega de bens ou mercadorias pertencentes à empresa; a manutenção de um estoque de bens ou mercadorias pertencentes à empresa unicamente para fins de armazenagem, exposição ou entrega ou para fins de sua transformação por outra empresa; a manutenção de uma instalação fixa de negócios unicamente para fins de comprar bens ou mercadorias ou obter informações para a empresa; as instalações fixas mantidas unicamente para fins de realizar qualquer outra atividade de caráter preparatório ou auxiliar e qualquer instalação mantida para a realização das atividades anteriormente mencionadas, desde que a atividade desenvolvida seja de caráter preparatório ou auxiliar.

O dispositivo estabelece, ainda, que os mandatários em um Estado Contratante que agem por conta de uma empresa do outro Estado Contratante serão considerados estabelecimentos permanentes no primeiro Estado, se tiverem, e exercerem habitualmente naquele Estado, autoridade para concluir contratos em nome da empresa, a não ser que suas atividades estejam elencadas dentre aquelas mencionadas no parágrafo anterior. Por outro lado, prevê que não serão consideradas como praticadas por estabelecimentos permanentes no outro Estado contratante as atividades realizadas no outro Estado por intermédio de um corretor, de um comissário geral ou de qualquer outro agente que goze de um status independente, desde que essas pessoas atuem no âmbito de suas atividades normais.

Por fim, o dispositivo prevê que o fato de uma sociedade residente de um Estado Contratante controlar ou ser controlada por uma residente no outro, ou que exerça sua atividade nesse outro Estado - seja ou não através de um estabelecimento permanente não será, por si só bastante para fazer de qualquer dessas sociedades estabelecimento permanente da outra.

\subsection{A LIVRE CONCORRÊNCIA NA TRIBUTAÇÃO DOS LUCROS}

Retornando às disposições do Modelo de Convenção, nota-se que os lucros de uma empresa de um Estado Contratante só são tributáveis nesse Estado, a não ser que a empresa exerça sua atividade no outro Estado Contratante por meio de um estabelecimento permanente aí situado. Isso significa que os lucros decorrentes de operações meramente transitórias são isentos no Estado onde está situada a fonte dos rendimentos, limitando, desse modo, a soberania fiscal do Estado. 
Outra limitação está prevista na parte final do dispositivo, o qual prevê que os lucros gerados no exterior por estabelecimentos serão tributáveis no Estado onde está situada a fonte dos rendimentos, mas unicamente na medida em que forem atribuíveis a esse estabelecimento permanente. Trata-se, novamente, de uma limitação à soberania fiscal do Estado da fonte.

Como critério para a determinação dos lucros, há a previsão de que, quando uma empresa de um Estado Contratante exercer sua atividade no outro Estado Contratante através de um estabelecimento permanente aí situado, serão atribuídos a este em cada Estado Contratante os lucros que obteria caso constituísse uma empresa distinta e separada, exercendo atividades idênticas ou similares, em condições idênticas ou similares, como se estivesse transacionando com absoluta independência com a empresa de que é um estabelecimento permanente. Aqui se tem a cláusula geral do respeito ao princípio da livre concorrência e a permissão para os ajustes dos preços de transferência nas transações entre partes associadas.

A fim de permitir a adequada apuração dos lucros, o Modelo de Convenção permite deduzir as despesas que tiverem sido feitas para a consecução dos objetivos do estabelecimento permanente, incluindo as despesas de direção e os encargos gerais de administração assim realizados, seja no local da situação do citado estabelecimento ou em outro local.

Como exceção, o Modelo de Convenção estabelece que, desde que seja usual no Estado Contratante determinar os lucros atribuíveis a um estabelecimento permanente com base em uma proporção dos lucros totais da empresa, a necessidade de observância do princípio da livre concorrência não irá impedir a tributação dos lucros determinados dessa forma. Em uma cláusula pouco esclarecedora, o dispositivo prevê que o resultado, entretanto, deverá estar de acordo com os princípios previstos no mencionado Artigo 7.

Há a previsão, ainda, de que nenhum lucro será atribuído a um estabelecimento permanente pelo simples fato de comprar bens ou mercadorias para a empresa.

Em respeito ao princípio contábil da uniformidade, o Modelo de Convenção prevê que os lucros serão estabelecidos, ano a ano, mediante a utilização do mesmo método, a menos que haja forte razão para a modificação. 
Por fim, o Modelo estabelece que, no caso de os lucros compreenderem elementos de rendimentos tratados separadamente em algum de seus outros artigos, serão aplicáveis as disposições desses artigos mais específicos.

\subsection{TRATAMENTO DISPENSADO ÀS EMPRESAS ASSOCIADAS}

Além das disposições gerais relativas à tributação dos lucros, o Modelo de Convenção estatui que, no caso de empresas associadas cujas relações comerciais ou financeiras sigam condições aceitas ou impostas que difiram das que seriam estabelecidas entre empresas independentes, os lucros que, sem essas condições, teriam sido obtidos por uma das empresas, mas não o foram por causa dessas condições, podem ser incluídos nos lucros dessa empresa e tributados como tal.

O dispositivo estabelece que as empresas são consideradas associadas quando uma empresa de um Estado Contratante participar direta ou indiretamente da direção, controle ou capital da outra empresa do outro Estado Contratante, ou quando as mesmas pessoas participam direta ou indiretamente da direção, controle ou capital de uma empresa de um Estado Contratante e de outra empresa do outro Estado Contratante.

Por fim, como forma de assegurar o adequado tratamento tributário dos lucros entre empresas independentes, o Modelo de Convenção determina que o ajuste promovido por um Estado contratante correspondente a um acréscimo nos lucros de uma empresa nele residente que sejam provenientes de outra empresa, situada no outro Estado contratante, com o intuito de ajustá-los, devem ser observados por este outro Estado.

Assim, o Estado no qual está situada a fonte dos rendimentos também deve promover um ajuste no montante dos tributos pagos sobre esses lucros, com o intuito de reduzi-los: trata-se, portanto, de um ajuste decorrente daquele inicialmente realizado pela administração tributária do outro Estado contratante. O dispositivo estabelece que, para esse propósito, deve ser dada especial atenção às demais disposições do Modelo de Convenção, bem assim que as autoridades competentes dos dois Estados poderão realizar consultas mútuas com o intuito de determinar o montante adequado de tributo. 


\subsection{ISENÇÃO OU IMPUTAÇÃO DO IMPOSTO}

Por fim, o Modelo de Convenção, de modo extremamente flexível, prevê duas alternativas para o tratamento em um dos Estados contratantes dos lucros já tributados nos estabelecimentos permanentes situados no outro Estado:

a) num deles, determina a isenção de tais valores, desde que o outro Estado contratante não tenha concedido isenção a tais rendimentos por força das disposições da Convenção ${ }^{33}$; e

b) no outro, determina a concessão de crédito correspondente ao valor do imposto sobre a renda pago no primeiro Estado, limitado ao valor de seu próprio imposto sobre a renda antes do cômputo dos rendimentos provenientes do outro Estado contratante ${ }^{34}$.

\subsection{CONSIDERAÇÕES ADICIONAIS SOBRE A CONTRIBUIÇÃO DA OCDE}

Além do Modelo de Convenção que vem aprimorando desde a década de 1960, a OCDE também tem se notabilizado pela edição de comentários sobre o Modelo de Convenção $0^{35}$, bem assim de um guia de orientação para as administrações tributárias em matéria de preços de transferência ${ }^{36}$. Neste guia, aliás, a OCDE propõe métodos para o ajuste dos lucros e procura apresentar exemplos de sua aplicação.

Apesar dessa notável contribuição, há algumas dificuldades relativas à aplicabilidade efetiva do Modelo de Convenção. A primeira delas diz respeito ao próprio processo de negociação das convenções internacionais com vistas à eliminação da dupla tributação, tendo em conta a diferença de interesses buscados pelos países em desenvolvimento e pelos países desenvolvidos. Os Estados em desenvolvimento concedem incentivos fiscais voltados para o investidor, esperando que o outro Estado contratante promova a eliminação da dupla tributação de modo a não eliminar tais incentivos.

33 Modelo A do Artigo 23.

Modelo B do Artigo 23.

35 ORGANISATION FOR ECONOMIC CO-OPERATION AND DEVELOPMENT. Model tax convention on income and capital: condensed version. Paris: OCDE, 2003.

36 Idem. Transfer Pricing: Guidelines for Multinational Enterprises and Tax Administrations Paris: OCDE, 2001. 
Entretanto, é notório que aqueles Estados não possuem adequado poder de barganha para assegurar seus interesses ${ }^{37}$.

Além disso, tendo em conta que podem surgir discordâncias acerca dos métodos utilizados para a promoção dos ajustes entre os Estados envolvidos, mesmo a via bilateral pode não resolver adequadamente a questão da dupla tributação internacional. Mencione-se, à guisa de exemplo, a preocupação da Comunidade Européia a qual, em 1990, editou a Diretiva no 436, conhecida como Convenção Arbitral, para tentar solucionar tais problemas.

\section{CONCLUSÃO}

Como visto, buscou-se, no presente trabalho, contextualizar a temática dos preços de transferência e suas relações com o problema da dupla tributação internacional. Procurou-se demonstrar que, apesar dos avanços já verificados na matéria, mormente os decorrentes da contribuição da OCDE, não se pode deixar de levar em conta o fato de que questões de ordem prática ainda se encontram sem solução, devendo, portanto, ser objeto de profunda reflexão não só pela doutrina, como também pelas diversas administrações tributárias existentes. Não se pretendeu, por evidente, o esgotamento do tema, mas sim propiciar subsídios para um futuro debate.

\section{REFERÊNCIAS BIBLIOGRÁFICAS}

GARCÍA, Nicolás Sánchez. La doble imposición internacional. In: Revista de Treball, Economia i Societat. número 16. Castelon: janeiro/ 2000. Disponível em <www.cescv.es/articulos_revista/ Revista_16/art2-rev16.pdf> Acesso em 9 out 2003.

HAMAEKERS, Hubert. The source principle versus the residence principle. Cadernos de Direito Tributário e Financas Públicas, v.1, n.3, p.164-175, abr./jun. 1993.

HINOJOSA MARTÍNEZ, Luis Miguel. La Regulación de los movimientos internacionales de capital desde una perspectiva europea. Madrid: McGraw Hill, 1997.

LACERDA, Antônio Correa de. Os Fluxos de investimentos e o papel das empresas transacionais. In Política Externa, vol. 12, n- 2, p. 5-22. set/out/nov 2003.

37 UNITED NATIONS. Manual for the negociation of bilateral tax treaties between developed and developing countries. New York: United Nations: 2003, p. 24. Disponível em <www.unpan.org> Acesso em 28 out 2003. 
ORGANISATION FOR ECONOMIC CO-OPERATION AND DEVELOPMENT. Articles of the model convention with respect to taxes on income and on capital: as they read on 28 January 2003. Disponível em <www.oecd.org> Acesso em 24 set 2003.

OCDE, 2003.

Model tax convention on income and capital: condensed version. Paris:

- Transfer Pricing: Guidelines for Multinational Enterprises and Tax Administrations Paris: OCDE, 2001.

. Transfer Pricing: Guidelines for Multinational Enterprises and Tax Administrations - overview. Disponível em www.oecd.org Acesso em 30 set 2003.

UNITED NATIONS. Draft manual for the negociation of bilateral tax treaties between developed and developing countries. New York: United Nations: 2001. Disponível em $<$ www.unpan.org > Acesso em 28 out 2003.

. Manual for the negociation of bilateral tax treaties between developed and developing countries. New York: United Nations: 2003. Disponível em $<$ www.unpan.org> Acesso em 28 out 2003.

. Transfer Pricing : History - State of the Art - Perspectives. Ad Hoc Group of Experts on International Cooperation in Tax Matters. Tenth meeting. Geneva, 10 14 September 2001. Disponível em <www.un.org> Acesso em 8 setembro 2003.

VOGEL, Klaus. Tributação da Renda Mundial. In: Cadernos de Direito Tributário e Finanças Públicas. Ano 2, número 7. São Paulo: Revista dos Tribunais, 1994, pp. 113143. 